\title{
Environmental and spatial drivers of taxonomic, functional, and phylogenetic characteristics of bat communities in human-modified landscapes
}

\author{
Laura M. Cisneros ${ }^{\text {Corresp., }} 1$ ， Matthew E. Fagan ${ }^{2}$, Michael R. Willig ${ }^{3,4}$ \\ ${ }^{1}$ Department of Natural Resources and the Environment, University of Connecticut, Storrs, Connecticut, United States \\ 2 Department of Geography and Environmental Systems, University of Maryland Baltimore County, Baltimore, MD, United States \\ 3 Department of Ecology and Evolutionary Biology, University of Connecticut, Storrs, Connecticut, United States \\ ${ }^{4}$ Center for Environmental Science and Engineering, University of Connecticut, Storrs, Connecticut, United States \\ Corresponding Author: Laura M. Cisneros \\ Email address: laura.cisneros@uconn.edu
}

Background. Assembly of species into communities following human disturbance (e.g. deforestation, fragmentation) may be governed by spatial (e.g. dispersal) or environmental (e.g. niche partitioning) mechanisms. Variation partitioning has been used to broadly disentangle spatial and environmental mechanisms, and approaches utilizing functional and phylogenetic characteristics of communities have been implemented to determine the relative importance of particular environmental (or niche-based) mechanisms. Nonetheless, few studies have integrated these quantitative approaches to comprehensively assess the relative importance of particular structuring processes.

Methods. We employed a novel variation partitioning approach to evaluate the relative importance of particular spatial and environmental drivers of taxonomic, functional, and phylogenetic aspects of bat communities in a human-modified landscape in Costa Rica. Specifically, we estimated the amount of variation in species composition (taxonomic structure) and in two aspects of functional and phylogenetic structure (i.e. composition and dispersion) along a forest loss and fragmentation gradient that are uniquely explained by landscape characteristics (i.e. environment) or space to assess the importance of competing mechanisms.

Results. The unique effects of space on taxonomic, functional and phylogenetic structure were consistently small. In contrast, landscape characteristics (i.e. environment) played an appreciable role in structuring bat communities. Spatially-structured landscape characteristics explained $84 \%$ of the variation in functional or phylogenetic dispersion, and the unique effects of landscape characteristics significantly explained $14 \%$ of the variation in species composition. Furthermore, variation in bat community structure was primarily due to differences in dispersion of species within functional or phylogenetic space along the gradient, rather than due to differences in functional or phylogenetic composition.

Discussion. Variation among bat communities was related to environmental mechanisms, especially niche-based (i.e. environmental) processes, rather than spatial mechanisms. High variation in functional or phylogenetic dispersion, as opposed to functional or phylogenetic composition, suggests that loss or gain of niche space is driving the progressive loss or gain of species with particular traits from communities along the human-modified gradient. Thus, environmental characteristics associated with landscape structure influence functional or phylogenetic aspects of bat communities by effectively altering the ways in which species partition niche space. 


\section{Environmental and spatial drivers of taxonomic, functional, and phylogenetic}

\section{2 characteristics of bat communities in human-modified landscapes}

3

4

5

6 Laura M. Cisneros ${ }^{1}$, Matthew E. Fagan ${ }^{2}$, and Michael R. Willig ${ }^{3,4}$

7

$8{ }^{1}$ Department of Natural Resources and the Environment, University of Connecticut, Storrs,

9 Connecticut, USA.

$10 \quad{ }^{2}$ Department of Geography and Environmental Systems, University of Maryland Baltimore

11 County, Baltimore, MD, United States

$12{ }^{3}$ Department of Natural Resources and the Environment, University of Connecticut, Storrs,

13 Connecticut, USA.

$14{ }^{4}$ Center for Environmental Sciences and Engineering, University of Connecticut, Storrs,

15 Connecticut, USA

16

17 Corresponding author: Laura M. Cisneros

18

19

20
1376 Storrs Road

Storrs, CT, 06268-4087, USA

laura.cisneros@uconn.edu 


\section{ABSTRACT}

22 Background. Assembly of species into communities following human disturbance (e.g.

23 deforestation, fragmentation) may be governed by spatial (e.g. dispersal) or environmental (e.g.

24 niche partitioning) mechanisms. Variation partitioning has been used to broadly disentangle spatial and environmental mechanisms, and approaches utilizing functional and phylogenetic characteristics of communities have been implemented to determine the relative importance of particular environmental (or niche-based) mechanisms. Nonetheless, few studies have integrated these quantitative approaches to comprehensively assess the relative importance of particular structuring processes.

Methods. We employed a novel variation partitioning approach to evaluate the relative importance of particular spatial and environmental drivers of taxonomic, functional, and phylogenetic aspects of bat communities in a human-modified landscape in Costa Rica. Specifically, we estimated the amount of variation in species composition (taxonomic structure) and in two aspects of functional and phylogenetic structure (i.e. composition and dispersion) along a forest loss and fragmentation gradient that are uniquely explained by landscape characteristics (i.e. environment) or space to assess the importance of competing mechanisms.

37 Results. The unique effects of space on taxonomic, functional and phylogenetic structure were consistently small. In contrast, landscape characteristics (i.e. environment) played an appreciable role in structuring bat communities. Spatially-structured landscape characteristics explained $84 \%$ of the variation in functional or phylogenetic dispersion, and the unique effects of landscape

41 characteristics significantly explained $14 \%$ of the variation in species composition. Furthermore, 42 variation in bat community structure was primarily due to differences in dispersion of species 
43 within functional or phylogenetic space along the gradient, rather than due to differences in

44 functional or phylogenetic composition.

45 Discussion. Variation among bat communities was related to environmental mechanisms, 46 especially niche-based (i.e. environmental) processes, rather than spatial mechanisms. High

47 variation in functional or phylogenetic dispersion, as opposed to functional or phylogenetic 48 composition, suggests that loss or gain of niche space is driving the progressive loss or gain of

49 species with particular traits from communities along the human-modified gradient. Thus,

50 environmental characteristics associated with landscape structure influence functional or

51 phylogenetic aspects of bat communities by effectively altering the ways in which species

52 partition niche space.

\section{INTRODUCTION}

An ongoing quest in ecology is to understand the relative importance of mechanisms that drive community assembly or disassembly. Variation in community structure (e.g. species composition) may arise due to niche-based processes (e.g. environmental filtering, niche partitioning) in which interspecific differences in ecological, morphological or physiological traits dictate species distributions and abundances along environmental gradients (Weiher and Keddy 1995). Alternatively, variation in community structure may arise as a consequence of

61 species-specific spatial dynamics, such as dispersal limitations (Legendre 1993). Nevertheless, environmental characteristics associated with niche-based processes are often spatially structured

63 so that environmental control on community structure may result in patterns that are similar to

64 those produced by spatial processes (i.e. induced spatial dependence; Legendre 1993). 
65 Disentangling the confounded effects of environmental and spatial processes on community

66 structure would significantly advance the conceptual underpinning of community ecology.

67

68

69

\section{Environment versus space}

A number of studies have addressed how to decouple the effects of space and environment. Indeed, variation partitioning (Borcard et al. 1992; Borcard and Legendre 1994) has become a routine procedure to differentiate among environmental and spatial mechanisms that structure communities (e.g. Legendre and Legendre 1998 and sources therein, Cottenie and De Meester 2004; Leibold et al. 2004; Cottenie 2005; Legendre et al. 2005; Peres-Neto et al. 2006 and sources therein; Stevens et al. 2007; Meynard et al. 2013). This approach provides a means to decompose variation in community structure into a proportion that is uniquely explained by environmental characteristics ([a] in Fig. 1) and a proportion that is uniquely explained by spatial characteristics ([c] in Fig. 1), by removing the environmental variation that is spatially structured ([b] in Fig. 1). Although findings from this approach provide broad understanding of the relative roles of environment and space in community assembly, they provide little insight on the importance of particular environmental or niche-based processes (e.g. environmental filtering, niche partitioning, or interspecific competition).

2 Approaches incorporating functional or phylogenetic characteristics of communities facilitate an assessment of the importance of particular environmental processes. Functional and phylogenetic aspects of communities use ecological traits and evolutionary histories of taxa, respectively, to differentially weight the presence of species. Also, phylogenetic patterns often can be interpreted with regard to ecological traits, as many traits exhibit strong phylogenetic signals (i.e. tendency of closely related species to have more similar ecological traits than 
88 expected by chance; Revell et al. 2008). Because the effects of environmental variation are

89 mediated by species characteristics (e.g. physiological constraints, habitat requirements, and

90 dispersal abilities), integration of assessments of functional and phylogenetic patterns into

91 approaches that broadly differentiate the influences of environmental or spatial factors can

92 provide resolution on competing mechanisms.

93 Functional or phylogenetic structure are each characterized by two general components:

94 mean location (hereafter composition) and dispersion. Composition characterizes the central

95 position of a community within functional or phylogenetic space based on the averages of

96 species characteristics (Fig. 2a), and is conceptually similar to community-weighted means

97 (Peres-Neto et al. 2012). Dispersion measures the distribution of all species in a community with

98 respect to functional or phylogenetic characteristics (Fig. 2b), and is conceptually similar to a

99 variety of metrics that measure functional diversity, such as Rao's quadratic entropy (Botta-

100 Dukát 2005). Environmental or spatial factors can cause variation in functional or phylogenetic

101 structure via (1) shifts in composition of communities with little effect on species dispersion

102 (Fig. 2c); (2) differences in the dispersion of species with little effect on composition (Fig. 2d);

103 or (3) changes in both composition and dispersion.

104 Until recently, a single method that decomposes total functional or phylogenetic structure

105 into the two components had not been developed (Peres-Neto et al. 2012). By determining the

106 relative importance of functional or phylogenetic components, we can better identify structuring

107 mechanisms associated with environmental factors. For example, significant variation in

108 functional or phylogenetic composition accompanied by little variation in functional or

109 phylogenetic dispersion suggests the operation of environmental filtering, in which communities

110 comprise species that have particular characteristics that are obligatory for persistence at that part 
111 of the gradient (Weiher and Keddy 1995; Mayfield and Levine 2010). In contrast, significant

112 variation in functional or phylogenetic dispersion accompanied by little variation in functional or

113 phylogenetic composition suggests the operation of mechanisms associated with variation in

114 niche partitioning (MacArthur and Levins 1967; Mayfield and Levine 2010). That is

115 communities may include more species with unique traits as more niches become available. The

116 relative importance of such niche-based mechanisms is dependent on the role of environmental

117 factors versus spatial factors.

118 To date, only one study has integrated variation partitioning and phylogenetic approaches

119 to comprehensively assess the relative importance of particular mechanisms (Gavilanez and

120 Stevens 2013). At a regional scale, they found that taxonomic structure and phylogenetic

121 structure of Neotropical primate communities were more influenced by spatial attributes than by

122 environmental or historical factors. Moreover, they found that partitioning of phylogenetic

123 structure revealed complex interactions among environmental, historical, and spatial processes.

\section{Landscape variation and bats}

126 Little is known about how landscape structure affects variation in functional or

127 phylogenetic aspects of communities (Tscharntke et al. 2012). Because fragmentation per se is a

128 mesoscale phenomenon when associated with human land-conversion (i.e. scales between local

129 and regional), processes that operate at mesoscales (e.g. environmental heterogeneity, landscape

130 connectivity, dispersal limitation; Leibold 2011) are likely to be influenced by both

131 environmental and spatial factors. As such, disentangling the effects of landscape characteristics

132 and space on variation in functional or phylogenetic attributes of communities can advance the

133 understanding of assembly or disassembly processes in human-modified landscapes. 

phylogenetic structure because they are diverse from taxonomic, evolutionary, and ecological

136 perspectives (Patterson et al. 2003). In the Neotropics, bats are generally the most species-rich

137 and locally abundant mammalian group, comprise species from a variety of feeding guilds (e.g.

138 frugivores, gleaning animalivores), and vary greatly in dispersal abilities (Patterson et al. 2003).

139 Moreover, bats provide important ecological functions, such as seed dispersal, pollination, and

140 regulation of insect populations (Kunz et al. 2011). Due to their diversity and ecological

141 importance in many tropical ecosystems, bats may be keystone taxa as well as bioindicators of

142 disturbance, as their responses to environmental variation may reflect the responses of other taxa

143 (Jones et al. 2009).

144 We employed a novel variation partitioning approach to comprehensively evaluate the

145 relative importance of particular environmental and spatial processes affecting taxonomic,

146 functional, and phylogenetic structure of bat communities within a human-modified landscape.

147 We estimated the unique and shared effects of landscape characteristics (i.e. environment) and

148 space on two components of functional and phylogenetic structure (i.e. composition and

149 dispersion) as well as on taxonomic structure (i.e. species composition). To provide further

150 insights on the importance of particular niche-based mechanisms, we examined the extent to

151 which variation in functional and phylogenetic structure was due to composition or dispersion.

152 Because bats are highly vagile, and variation in a variety of ecological and evolutionary aspects

153 of bat communities is influenced by landscape characteristics (Gorresen et al. 2005; Klingbeil

154 and Willig 2009; García-Morales et al. 2013; Cisneros et al. 2015a; Cisneros et al. 2015b; Meyer

155 et al. 2015), we predict that unique effects of landscape structure account for more variation in

156 taxonomic, functional, and phylogenetic structure than do unique effects of space. Nevertheless, 
157 we expect the effects of landscape characteristics to be more pronounced on functional and

158 phylogenetic structure than on taxonomic structure based on the assumption that particular

159 landscape characteristics select for species with particular traits.

160

\section{MATERIALS \& METHODS}

\section{Study area and sites}

163 Research was conducted in a human-modified landscape of the Caribbean lowlands in 164 northeastern Costa Rica (Fig. 3). The 160,000 hectare landscape encompasses fragments of wet

165 tropical forest at various successional stages (e.g. old-growth and secondary forests), a variety of 166 agricultural plantations (e.g. heart of palm, banana, and pineapple), cattle pastures, and logged

167 areas. The climate is warm and moist, with relatively constant temperatures throughout the year 168 (mean daily temperature: $31.0^{\circ} \mathrm{C}$; range: $30.2-31.9^{\circ} \mathrm{C}$ ) and appreciable rainfall every month 169 (mean annual precipitation: $4374.6 \mathrm{~mm}$; range: 2809.3-6164.0 mm; Organization for Tropical 170 Studies 2012). In general, a drier period occurs from January to late April, with mean monthly 171 rainfall of $223.7 \mathrm{~mm}$, followed by a wet period from early May to December, with mean monthly 172 rainfall of $435.0 \mathrm{~mm}$. Nevertheless, the dry and wet seasons during this study (2010) were less 173 distinct (i.e. mean monthly rainfall was $353.8 \mathrm{~mm}$ in the dry season and $431.4 \mathrm{~mm}$ in the wet 174 season). Because of changes in resource availability and resource requirements of bats between

175 seasons (Frankie et al. 1974; Tschapka 2004), analyses were conducted separately for the dry and 176 wet seasons.

$177 \quad$ Fifteen circular sites (5 km radius) were established across the landscape so that centers 178 were positioned within forest patches and were separated by at least $3.5 \mathrm{~km}$ (Fig. 3). These sites 179 were selected to represent a forest loss and fragmentation gradient that encompasses the current 
180 range in composition and configuration of forest land cover in the study area (Table S1). Site

181 selection was not stratified or randomized because of limitations associated with gaining

182 permission from owners to access land and because landscape structures were not equally

183 accessible.

184

185 Data

186 Biological surveys

187 Bats were surveyed using ground-level mist nets during the dry season (January to April)

188 and wet season (May to September) of 2010. These surveys provided information on species

189 composition and abundances that were used to quantify taxonomic, functional and phylogenetic

190 structure. Each site was surveyed four times each season. For each survey, 12 mist nets (12 m x

$1912.5 \mathrm{~m}$ ) were opened for six hours from dusk until midnight (mist nets were inspected every 30

192 minutes). Mist nets were deployed in trails and flyways in closed-canopy forest within $1 \mathrm{~km}$ of

193 the center of each site. Sampling was not conducted during the presence of a moon that was $\geq$

$19490 \%$ full due to reduced bat activity associated with high lunar illumination (Morrison 1978) or

195 during severe weather because of health risks to bats from exposure to low temperatures

196 associated with strong winds or rain. To identify recaptures within a sampling period, hair was

197 trimmed on the back of each bat before it was released. The use of ground-level mist nets,

198 unaccompanied by other sampling methods, effectively samples species from the family

199 Phyllostomidae (Kalko 1997), but may under-represent species in other families (Kalko and

200 Handley 2001). Accordingly, analyses were limited to phyllostomids. The protocol for animal

201 use for this research was approved by the IACUC at the University of Connecticut (IACUC

202 number: A09-014). A field research permit was issued by the Sistema Nacional de Áreas de 
203 Conservación del Ministerio del Ambiente y Energia of Costa Rica (permit number: 003-2010-

204 SINAC).

205

206 Functional and phylogenetic characteristics

207 Functional characteristics were based on 27 categorical (binary) and mensural attributes

208 that represented seven niche axes (Table S2). Use of multiple niche axes and multiple attributes

209 within niche axes is critical to comprehensively represent functions of species in the ecosystem.

210 Categorical niche axes were associated with (1) diet, (2) foraging location, (3) foraging strategy,

211 and (4) roost type. Mensural niche axes were associated with (1) body size, (2) masticatory mode

212 (i.e. skull characteristics), and (3) aerodynamic mode (i.e. wing characteristics). For each

213 categorical attribute, a species received a " 1 " if it exhibited the characteristic or a " 0 " if it did not

214 exhibit the characteristic. For each mensural attribute, an average value was obtained for each

215 species based on measurements of multiple male and female adults ( $\geq 2$ individuals).

216 Information for functional attributes was derived from the literature and restricted to

217 records from Central America when possible (Table S3). Additionally, measurements of size

218 attributes were augmented by field measurements from the study area. Missing mensural data

219 were estimated using the least squares regression line between mass and the particular attribute

220 using known values of other species from the same subfamily. Missing categorical data were

221 replaced by values from congeners. Only $4.1 \%$ of species traits were estimated or replaced (i.e.

22238 of 918 traits).

223 Functional differences between species were obtained using the Gower metric (R

224 package "clusters"; Maechler et al. 2012) and were represented in a pairwise distance matrix.

225 The Gower metric can quantify dissimilarities when simultaneously considering categorical and 
226 mensural attributes (Botta-Dukát 2005). Using this metric, functional dissimilarity between

227 species is the sum of the weighted functional trait differences. When all niche axes were used to

228 derive the distance matrix, we weighted attributes such that each niche axis had equal influence

229 on overall structure despite having unequal numbers of attributes. Equal weights were assigned

230 because we have little a priori knowledge of which functional niche axes are most important to

231 community assembly. This weighting approach also decreases sensitivity of the analyses to

232 potentially redundant attributes. We also conducted analyses for each functional niche axis

233 separately (Table S2) because the environmental gradient may affect functional niche axes

234 differently (see Cisneros et al. 2015a). Thus, integrating all ecological attributes into a single

235 multivariate measure may obscure important patterns (Spasojevic and Suding 2012).

236 Phylogenetic characteristics were based on branch lengths from a species-level supertree

237 of bats (Jones et al. 2005). Five of the 34 species were not present in this supertree. The closest

238 congener present in the supertree that was not present in the study area was substituted for each

239 missing species. Although a number of phylogenetic trees are available for bats, the supertree

240 developed by Jones et al. (2005) represents the most complete and accepted tree. Moreover,

241 higher-level divergences in the selected supertree are consistent with those in other phylogenetic

242 trees (Jones et al. 2005), and these cladistics events have the predominant effect on phylogenetic

243 characteristics of community structure. Phylogenetic distances between species were calculated

244 via the "cophenetic" function of the R package "ape" (Paradis et al. 2004) and represented in a

245 pairwise dissimilarity matrix.

246

247 Environmental characteristics 

represented the landscape of 2011 (see Fagan et al. 2013 for a detailed description of map construction). The original 13 cover types were reclassified into six cover types: forest (i.e. mature forest, swamp forest, native reforestation, and exotic tree plantations), cropland (i.e.

252 banana, sugarcane, heart of palm, and pineapple), pasture, bare soil, urban, and water. Pixel 253 values that were originally designated as masked areas (i.e. areas obscured by cloud or Landsat 7 254 line errors; $0.6 \%$ of land cover) were manually changed to other pixel values within which they were embedded or to pixel values based on a 2005 land cover map of the study area (Fagan et al. 2013) using the area fill tool in ERDAS IMAGINE 2013.

Five compositional (i.e. percent forest, percent pasture, mean forest patch size, forest patch density, and Simpson's diversity of cover types; Table S4) and four configurational (i.e. mean forest proximity, mean forest nearest neighbor, mean forest patch shape, and forest edge density; Table S4) landscape indices were quantified using FRAGSTATS version 4 (McGarigal et al. 2012). Composition refers to the proportions of different types of land cover within a site, whereas configuration reflects the geometric arrangement of land cover within a site. All indices were quantified using forest as the focal land cover type, except for percent pasture and Simpson's diversity of cover types. Spatial patterns are scale dependent, and the scale at which bats use and respond to the environment is species-specific (Gorresen et al. 2005; Klingbeil and Willig 2009). Thus, all landscape characteristics were quantified at each of three spatial scales

267 (circles of 1,3 , and $5 \mathrm{~km}$ radius) to account for interspecific differences in bat home range size 268 and behavior, as well as to facilitate comparison with other studies on landscape ecology on 269 Neotropical bats. 
271

272

273

274

275

276

277

278

279

280

281

282

283

284

285

286

287

288

289

290

291

292

293

\section{Spatial characteristics}

Spatial predictors were estimated from Moran's eigenvector maps (MEMs; Dray et al. 2006). MEMs provide a more powerful means to describe spatial effects at a variety of scales, can explain more variation in species data than can geographic coordinates or polynomial functions of geographic coordinates, and better control for type I error rates associated with unique environmental effects (Legendre et al. 2005; Peres-Neto and Legendre 2010). To derive these eigenvectors, we first use geographic coordinates of the sites to create a distance matrix. From the distance matrix, a connectivity matrix is constructed based on a threshold distance and minimum spanning tree algorithm. Finally, eigenvectors were computed from the centered connectivity matrix. A single eigenvector associated with a large and positive eigenvalue was used as the spatial predictor because it represents positive spatial autocorrelation and a landscape-wide spatial trend (however, the six MEMs representing different spatial scales all yielded similar results). Construction of MEMs was completed using algorithms written in Matlab by Peres-Neto et al. (2012).

\section{Statistical analysis}

Variation partitioning was conducted for taxonomic, functional, and phylogenetic structure for each combination of season (i.e. dry and wet) and scale (i.e. 1, 3, $5 \mathrm{~km}$ ). First, structure for each dimension was quantified using a site-by-species abundance matrix as follows:

1) Taxonomic structure-a matrix representing variation in species composition was obtained by employing a Hellinger transformation on the site-by-species abundance matrix. This transformation gives low weights to species that are rare at particular sites and infrequent at most sites (Legendre and Gallagher 2001). Dispersion cannot 
be quantified for taxonomic structure because all species are considered equally different from one another (i.e. nominal data); thus, there is no variation in interspecific differences.

2) Functional and phylogenetic structure-vectors representing variation in functional (or phylogenetic) composition and dispersion were quantified using the methodologies of Peres-Neto et al. (2012). First, total functional (or phylogenetic) variation was quantified by linking the site-by-species abundance matrix with an eigenvector representing functional (or phylogenetic) variation among species (eigenvector was derived from a functional or phylogenetic distance matrix) via the Hadamard element-wise multiplier. The total functional (or phylogenetic) variation matrix was weighted based on the sum of the occurrences of each species to minimize the effects of rare species. Next, the total functional (or phylogenetic) variation matrix was decomposed into the composition component $\left(\bar{X}_{F}\right.$ or $\left.\bar{X}_{P}\right)$ and the dispersion component $\left(s_{F}\right.$ or $\left.s_{P}\right)$ by re-distributing the sum-of-squares of the total variation matrix in terms of means and variances among sites.

311 composition $\left(\bar{X}_{F}\right.$ or $\left.\bar{X}_{P}\right)$, or functional (or phylogenetic) dispersion $\left(s_{F}\right.$ or $\left.s_{P}\right)$ into variation

312 explained by environmental (i.e. landscape characteristics) and spatial (i.e. MEM) predictors.

313 Three weighted least-squares regressions quantifying 1) variation explained by both sets of

314 predictors (E and S in Fig. 1), 2) variation explained by only the environmental predictors (E in

315 Fig. 1), and 3) variation explained by only the spatial predictor (S in Fig. 1) were used to 316 subsequently partition total variation into four fractions (i.e. unique environmental effects after 
317 accounting for space [a], spatially-structured environmental effects [b], unique spatial effects

318 after accounting for environment [c], and residual variation [d]; Fig. 1). In each regression,

319 adjusted $R^{2}$ was quantified to minimize the bias associated with the number of independent

320 variables and sample size (Peres-Neto et al. 2006).

321 Two permutation procedures were used to test for statistical significance of the unique

322 contributions of environment and space (i.e. fractions [a] and [c], respectively). For taxonomic

323 structure, 1000 permutations of the community matrix were conducted. For functional or

324 phylogenetic structure, we employed a procedure developed by Peres-Neto et al. (2012) that

325 permutes site vectors in the predictor matrix (E or S) 1000 times and permutes species vectors in

326 the functional or phylogenetic eigenvector 1000 times. Variation partitioning of taxonomic

327 structure, and associated permutation procedures, were conducted using the function varpart

328 from the R package "vegan" (Oksanen et al. 2009). Variation partitioning of functional or

329 phylogenetic structure, and associated permutation procedures, were conducted with algorithms

330 written in Matlab by Peres-Neto et al. (2012).

332 RESULTS

333

Along the forest loss and fragmentation gradient, bat communities exhibited significant

334 variation in structure with regard to species richness (sites ranged from 9-19 species in dry

335 season and 6-20 species in wet season) and abundance (sites ranged from 30-272 individuals in

336 dry season and 16-202 individuals in wet season). In addition, variation in ecological and

337 evolutionary aspects of community structure characterized the gradient, but was primarily due to

338 dispersion $\left(s_{F}\right.$ and $\left.s_{P}\right)$ rather than composition $\left(\bar{X}_{F}\right.$ and $\bar{X}_{P}$; Table S5). That is, the average

339 functional or phylogenetic characteristic of each bat community (i.e. composition; $\bar{X}_{F}$ and $\bar{X}_{P}$ ) 
340 was essentially the same for all sites, but the breath of functional or phylogenetic characteristics

341 (i.e. dispersion; $s_{F}$ and $s_{P}$ ) exhibited by each community differed among sites. Because little

342 variation in functional or phylogenetic composition characterized bat communities within the

343 study area, only results from analyses using dispersion as the response variable (Fig. 4b, c,

344 Tables S6 and S7; but see Table S8 for variation partitioning results of $\bar{X}_{F}$ and $\bar{X}_{P}$ ), in addition to

345 species composition, are discussed hereafter.

346 The total variation in species composition (i.e. taxonomic structure) of bat communities

347 that was explained by both environmental and spatial predictors ranged from 15.0 to $39.4 \%$ in

348 the dry season and from 0 to $15.3 \%$ in the wet season (see Tables S6 and S7). Most of the

349 variation in species composition was explained by the unique effects of landscape characteristics

350 ([a] in Fig. 4a); however, these significant effects were limited to the dry season at $3 \mathrm{~km}$ and 5

$351 \mathrm{~km}$ focal scales.

352 In contrast, the total variation in functional or phylogenetic dispersion that was explained

353 by both environmental and spatial predictors ranged from 90.6 to $99.9 \%$, regardless of season or

354 scale (Tables S6 and S7). Unique effects of landscape characteristics ([a] in Fig. 4b, c, Table S7)

355 and unique effects of space ([c] in Fig. 4b, c, Table S7) on variation in functional or phylogenetic

356 dispersion were relatively small compared to effects of spatially-structured landscape

357 characteristics ([b] in Fig. 4b, c, Table S7). On average, spatially-structured landscape

358 characteristics accounted for $\sim 84 \%$ of the variation in functional or phylogenetic dispersion,

359 whereas unique effects of landscape characteristics and unique effects of space accounted for

$36012 \%$ and $\sim 1 \%$ of variation in functional or phylogenetic dispersion, respectively. Although the

361 unique effects of landscape characteristics and the unique effects of space on functional or 
362 phylogenetic dispersion were small, a few were significant at $3 \mathrm{~km}$ and $5 \mathrm{~km}$ scales during the

363 dry season (Fig. 4b, Table S7).

364

365 DISCUSSION

This is one of the first studies to employ a novel variation partitioning approach for

367 multiple dimensions of community structure, including the decomposition of functional and

368 phylogenetic structure into composition and dispersion components. Through this approach, we

369 comprehensively evaluated the relative importance of various environmental and spatial

370 processes driving community assembly or disassembly within a human-modified landscape.

371

372 Relative roles of environmental and spatial mechanisms

373 Forest loss and fragmentation due to human land use is a mesoscale phenomenon (i.e.

374 between local and regional scales). As such, a number of environmental or spatial processes may

375 influence communities (e.g. environmental heterogeneity, landscape connectivity, dispersal

376 limitation; Leibold 2011). Indeed both significant effects of landscape structure and significant

377 effects of space on community structure have been reported at the meso-scale. For tropical dry

378 forests, both unique effects of landscape structure and unique effects of space played significant

379 roles in governing species density (Hernández-Stefanoni et al. 2011). Conversely, the amount of

380 different land cover types, as opposed to space and configurational characteristics of the

381 landscape, had unique effects on species composition of avian communities (Heikkinen et al.

382 2004). In this study, landscape characteristics played a more appreciable role in structuring

383 Neotropical bat communities, whereas effects that were uniquely attributed to space were

384 consistently small (Fig. 4b, c, Tables S6 and S7). The strong role of environmental mechanisms, 
385 more so than spatial mechanisms, during community assembly in human-modified landscapes is

386 likely a common theme for mobile taxa that are not as limited by dispersal.

387 From the perspective of all three dimensions, landscape characteristics were important in

388 molding bat communities. However, landscape characteristics that were not confounded with

389 space dictated species composition (i.e. taxonomic structure; Fig. 4a), whereas spatially-

390 structured landscape characteristics dictated the breath of functional or phylogenetic

391 characteristics (i.e. dispersion) of communities (Fig. 4b, c, Table S7). First, the influences of

392 spatially-structure landscape characteristics were not due to space per se. This is supported by a

393 lack of spatial autocorrelation in functional or phylogenetic structure of bat communities (Table

394 S9). Second, the difference in landscape effects suggests that processes structuring different

395 aspects of bat communities operate at different scales. Landscape characteristics within $5 \mathrm{~km}$ of

396 centers of sites were not spatially autocorrelated (Table S10), but landscape patterns at scales

397 larger than $5 \mathrm{~km}$ around sites were inherently spatially autocorrelated due to the nature of land

398 use in the study area (e.g. clustering of certain land cover types; Fig. 3). Thus, broad landscape

399 patterns ( $>5 \mathrm{~km}$ around sites) influenced community assembly via species ecological or

400 evolutionary characteristics, whereas smaller landscape patterns ( $\leq 5 \mathrm{~km}$ around sites) influenced

401 the species composition of bat communities.

402 The strength of landscape effects differed between seasons, with more prominent effects

403 during the dry season. Season-specific responses to human land conversion and land use have

404 been observed in other bat communities in Latin America (Willig et al. 2007; Klingbeil and

405 Willig 2010). The increased importance of landscape structure to Caribbean lowland bat

406 communities in the dry season is likely driven by a decrease in resource quantity and diversity

407 during this time of year (Frankie et al. 1974; Tschapka 2004). In another study, we found that bat 
408 species concentrate activities at sites with particular landscape structures that were associated

409 with the presence of diverse food resources during times of limitation, whereas when food

410 resources were more plentiful, bat species were not restricted to sites with particular landscape

411 characteristics (Cisneros et al. 2015b).

412 During the dry season, unique effects of space had small but significant influences on the

413 breath of diet and morphological traits of bat communities (Table S7). These effects could

414 represent the influences of unmeasured environmental characteristics or the influences of

415 dispersal limitations, which may restrict bats with particular morphological traits or diet

416 requirements to particular sites. Dispersal may become especially important during the dry

417 season as species may need to use a greater number of resources patches to meet dietary

418 demands (Sih 2011).

419

420

\section{Effects on dispersion versus composition}

Landscape and spatial predictors explained different amounts of variation in each

422

423

424

425

426

427

428

429

430

dimension. Both sets of predictors explained relatively little variation in species composition (i.e. taxonomic structure), but explained most of the variation in functional or phylogenetic dispersion (Table S6). This difference is due to disparate effects of landscape structure on composition and dispersion aspects of bat communities in the Caribbean lowlands. Species (i.e. taxonomic), functional and phylogenetic composition did not differ greatly among communities because a subset of species from the genera Artibeus and Carollia (i.e. genera within clades 1 and 2 in Fig. 5) were present in moderate to high abundances at all sites. Given that these abundant species have similar functional characteristics (e.g. species primarily consume fruit) and positions in the bat phylogeny, little inter-site variation characterized average taxonomic, functional and 
431 phylogenetic structure throughout the study landscape. Accordingly, composition did not capture

432 variation in bat community structure, and varied little with regard to the environmental and 433 spatial gradient.

434 Variation in the breath of functional and phylogenetic characteristics (i.e. dispersion) of 435 communities primarily described changes in bat community structure. This variation in structure 436 arose as some sites only had the most abundant frugivorous species from the genera Artibeus and 437 Carollia, where others comprised additional species that were less abundant from the subfamilies 438 Glossophaginae, Phyllostominae, and Desmodontinae (clades 3, 4, and 5 in Fig. 5). These rarer 439 species possess different functional characteristics from those species in the genera Artibeus and 440 Carollia (e.g. species consume nectar or pollen, invertebrates or vertebrates and blood, 441 respectively); thus, communities comprising these species were characterized with a greater 442 diversity of functional and phylogenetic characteristics. As such, processes driving community 443 assembly or disassembly of Neotropical bats in human-modified landscapes likely operate by 444 creating or destroying environmental features that support these non-frugivorous species.

446 Relative roles of specific environmental mechanisms

447 Decomposition of total functional and phylogenetic structure into composition and 448 dispersion provides valuable ecological insights into niche-based (i.e. environmental) 449 mechanisms driving community assembly or disassembly, especially the relative roles of 450 environmental filtering and niche partitioning. Environmental filtering is a process by which 451 species with particular characteristics are unable to persist or establish at a part of the 452 environmental gradient because they are not well adapted or are poor competitors (Weiher and 453 Keddy 1995; Mayfield and Levine 2010). A large influence of environmental filtering in 
454 community assembly would manifest through significant shifts in functional or phylogenetic

455 composition. Niche partitioning mechanisms (e.g. interspecific competition, variation in

456 productivity, creation or loss of habitats) reduce or increase the number of potential niches

457 available to species (MacArthur and Levins 1967; Mayfield and Levine 2010). A significant role

458 of niche partition mechanisms in community assembly would impact the breath or dispersion of

459 functional or phylogenetic characteristics of communities, such as in the case of this study.

$460 \quad$ Human land use and land conversion in the Caribbean lowlands impacts bat communities

461 by modifying niche availability for less common species from the subfamilies Glossophaginae,

462 Phyllostominae, and Desmodontinae. One possible niche partitioning mechanisms relevant to

463 human-modified landscapes is restricted niche availability due to habitat loss or landscape

464 homogenization (e.g. landscapes dominated by monocultures; Devictor et al. 2008; Flynn et al.

465 2009). This mechanism is particularly relevant to phyllostomid bats, as most species generally

466 avoid sun-grown monocultures, and species of the subfamily Phyllostominae are generally

467 dependent on complex vegetation structure (García-Morales et al. 2013).

468 Another potential niche partitioning mechanism relevant to phyllostomid bats arises from

469 the creation of a diversity of new habitats (i.e. increasing landscape heterogeneity due to only

470 moderate amounts of human land use). Many resources used by phyllostomids can be obtained

471 from human-modified environments (i.e. forest edge, pasture and non-monoculture agricultural

472 systems; Wilkinson 1985; Lobova et al. 2003; Thies and Kalko 2004; Harvey and González

473 Villalobos 2007). In fact, nectarivores and sanguinivores were more common at sites with a mix

474 of agriculture, pasture and forest than at sites dominated by forest (Fig. 5), as these taxa feed on

475 flowers and fruits from early successional plants and crops (Lobova et al. 2003; Harvey and

476 González Villalobos 2007) and on blood from cattle (Wilkinson 1985), respectively. Indeed, 
477 areas with intermediate amounts of forest and pasture harbored higher levels of functional and

478 phylogenetic bat diversity in the Caribbean lowlands during the dry season (Cisneros et al.

479 2015a). Accordingly, increasing niche availability that accompanies increasing landscape

480 heterogeneity is likely the primary driver of community assembly of phyllostomid bats in the

481 Caribbean lowlands.

482

483 CONCLUSIONS

484 By linking taxonomic, functional and phylogenetic community structure to approaches

485 based on variation partitioning facilitates a more comprehensive assessment of environmental

486 and spatial mechanisms that drive community assembly. Community structure of Neotropical

487 bats in a human-modified landscape was primarily molded by large-scale environmental

488 variation associated with landscape structure, rather than by spatial processes. Landscape

489 structure influenced bat communities via increasing or decreasing niche availability along the

490 human-modified landscape gradient.

491

492 ACKNOWLEDGEMENTS

493 Special thanks to R. Chazdon, D. Civco, B. Klingbeil, S. Presley and M. Urban for

494 guidance in the analytical component of this research, to B. Rodríguez Herrera and A. Sanchun

495 for guidance in the field, and to R. Urbina, H. Lara Perez, K. Díaz Hernández and S. Padilla

496 Alvarez for assistance with field work. We also thank P. Peres-Neto for helpful discussions on

497 methodologies, and W. Pineda Lizano and C. Meyer for contributions of unpublished

498 measurements of wing characteristics. Logistical support in Costa Rica was provided by

499 Tirimbina Biological Reserve, La Selva Biological Station, Fundación para el Desarrollo de la 
500 Cordillera Volcánica Central (FUNDECOR), Ministerio de Ambiente (MINAE), the Wildlife

501 Refuge Nogal, Selva Verde Lodge and Rainforest Reserve, Hacienda Pozo Azul, and two local

502 landowners.

503

504 REFERENCES

505 Borcard D, Legendre P (1994) Environmental control and spatial structure in ecological

506 communities: an example using oribatid mites (Acari, Oribatei). Environ Ecol Stat 1: 37-

$507 \quad 61$

508 Borcard D, Legendre P, Drapeau P (1992) Partialling out the spatial component of ecological $509 \quad$ variation. Ecology 73: 1045-1055

510 Botta-Dukát Z (2005) Rao’s quadratic entropy as a measure of functional diversity based on

$511 \quad$ multiple traits. J Veg Sci 16: 533-540

512 Cisneros LM, Fagan ME, Willig MR (2015a) Effects of human-modified landscapes on

513 taxonomic, functional and phylogenetic dimensions of bat biodiversity. Divers Distrib 21:

$514 \quad 523-533$

515 Cisneros LM, Fagan ME, Willig MR (2015b) Season-specific and guild-specific effects of 516 anthropogenic landscape modification on metacommunity structure of tropical bats. J Anim $517 \quad$ Ecol 84: 373-385

518 Cottenie K (2005) Integrating environmental and spatial processes in ecological community 519 dynamics. Ecol Lett 8: 1175-1182

520 Cottenie K, De Meester L (2004) Metacommunity structure: synergy of biotic interactions as $521 \quad$ selective agents and dispersal as fuel. Ecology 85: 114-119 
522 Devictor V, Julliard R, Clavel J, Jiguet F, Lee A, Couvet D (2008) Functional biotic

523 homogenization of bird communities in disturbed landscapes. Glob Ecol Biogeogr 17: 252-

$524 \quad 261$

525 Dray S, Legendre P, Peres-Neto PR (2006) Spatial modelling: a comprehensive framework for 526 principal coordinate analysis of neighbour matrices (PCNM). Ecol Model 196: 483-493

527 Fagan ME, DeFries RS, Sesnie SE, Arroyo JP, Walker W, Soto C, Chazdon RL, Sanchun A 528 (2013) Land cover dynamics following a deforestation ban in northern Costa Rica. Environ $529 \quad$ Res Lett 8: 034017

530 Flynn DFB, Gogol-Prokurat M, Nogeire T, Molinari N, Trautman Richers B, Lin BB, Simpson

531 N, Mayfield MM, DeClerck F (2009) Loss of functional diversity under land use

532 intensification across multiple taxa. Ecol Lett 12: 22-33

533 Frankie GW, Baker HG, Opler PA (1974) Comparative phenological studies of trees in tropical

534 wet and dry forest in the lowlands of Costa Rica. J Ecol 62: 881-919

535 García-Morales R, Badano EI, Moreno CE (2013) Response of Neotropical bat assemblages to

536 human land use. Conserv Biol 27: 1096-1106

537 Gavilanez MM, Stevens RD (2013) Role of environmental, historical and spatial processes in the

538 structure of Neotropical primate communities: contrasting taxonomic and phylogenetic

539 perspectives. Glob Ecol Biogeogr 22: 607-619

540 Gorresen PM, Willig MR, Strauss, RE (2005) Multivariate analysis of scale-dependent

541 associations between bats and landscape structure. Ecol Appl 15: 2126-2136

542 Harvey CA, González Villalobos JA (2007) Agroforestry systems conserve species-rich but

543 modified assemblages of tropical birds and bats. Biodivers Conserv 16: 2257-2292 
544 Heikkinen RK, Luoto M, Virkkala R, Rainio K (2004) Effects of habitat cover, landscape

545 structure and spatial variables on the abundance of birds in an agricultural-forest mosaic. J

$546 \quad$ Appl Ecol 41: 824-835

547 Hernández-Stefanoni JL, Dupuy JM, Tun-Dzul F, May-Pat F (2011) Influences of landscape

548 structure and stand age on density and biomass of a tropical forest across scales. Landscape

$549 \quad$ Ecol 26: $355-370$

550 HilleRisLambers J, Adler PB, Harpole WS, Levine JM, Mayfield MM (2012) Rethinking

551 community sssembly through the lens of coexistence theory. Annu Rev Ecol Evol Syst 43:

$552 \quad 227-248$

553 Jones KE, Bininda-Emonds ORP, Gittleman JL (2005) Bats, clocks, and rocks: diversification

554 patterns in Chiroptera. Evolution 59: 2243-2255

555 Jones G, Jacobs DS, Kunz TH, Willig MR, Racey PA (2009) Carpe noctem: the importance of

556 bats as bioindicators. Endanger Species Res 8: 93-115

557 Kalko EKV (1997) Diversity in tropical bats. In Ulrich H (ed) Tropical biodiversity and

558 systematics. Zoologisches Forschungsinstitut und Museum Alexander Koenig, Bonn,

$559 \quad$ Germany, pp 13-43

560 Kalko EKV, Handley CO (2001) Neotropical bats in the canopy: diversity, community structure,

561 and implications for conservation. Plant Ecol 153: 319-333

562 Klingbeil BT, Willig MR (2009) Guild-specific responses of bats to landscape composition and

563 configuration in fragmented Amazonian rainforest. J Appl Ecol 46: 203-213

564 Klingbeil BT, Willig MR (2010) Seasonal differences in population-, ensemble- and community-

565 level responses of bats to landscape structure in Amazonia. Oikos 119: 1654-1664 
566 Kunz TH, Braun de Torrez E, Bauer D, Lobova T, Fleming TH (2011) Ecosystem services

567 provided by bats. Ann NY Acad Sci 1223: 1-38

568 Lavorel S, Grigulis K, McIntyre S, Williams NSG, Garden D, Dorrough J, Berman S, Quétier F, 569 Thébault A, Bonis A (2008) Assessing functional diversity in the field - methodology $570 \quad$ matters! Funct Ecol 22: 134-147

571 Legendre P (2008) Studying beta diversity: ecological variation partitioning by multiple regression and canonical analysis. J Plant Ecol 1: 3-8

573 Legendre P (1993) Spatial autocorrelation: trouble or new paradigm? Ecology 74: 1659-1673

574 Legendre P, Borcard D, Peres-Neto PR (2005) Analyzing beta diveristy: partitioning the spatial 575 variation of community composition data. Ecol Monogr 75: 435-450

576 Legendre P, Gallagher ED (2001) Ecologically meaningful transformations for ordination of 577 species data. Oecologia 129: 271-280

578 Legendre P, Legendre L (1998) Numerical ecology, $2^{\text {nd }}$ edn. Elsevier Science, Amsterdam, $579 \quad$ Netherlands

580 Leibold MA (2011) The metacommunity concept and its theoretical underpinnings. In Scheiner 581 SM, Willig MR (eds) The theory of ecology. University of Chicago Press, Chicago, $582 \quad$ Illinois, USA, pp. 163-184

583 Leibold MA, Holyoak M, Mouquet N, Amarasekare P, Chase JM, Hoopes MF, Holt RD, Shurin 584 JB, Law R, Tilman D, Loreau M, Gonzalez A (2004) The metacommunity concept: a 585 framework for multi-scale community ecology. Ecol Lett 7: 601-613

Lobova TA, Mori SA, Blanchard F, Peckham H, Charles-Dominique P (2003) Cecropia as a food resource for bats in French Guiana and the significance of fruit structure in seed dispersal and longevity. Am J Bot 90: 388-403 
589 MacArthur R, Levins R (1967) The limiting similarity, convergence, and divergence of

$590 \quad$ coexisting species. Am Nat 101: 377-385

591 Maechler M, Rousseeuw P, Struyf A, Hubert M, Hornik K (2012) Cluster: cluster analysis basics

$592 \quad$ and extensions. R package version 1.14.4

593 Mayfield MM, Levine JM (2010) Opposing effects of competitive exclusion on the phylogenetic 594 structure of communities. Ecol Lett 13: 1085-1093

595 McGarigal K, Cushman SA, Ene E (2012) FRAGSTATS v4: spatial pattern analysis program for 596 categorical and continuous maps. University of Massachusetts, Amherst, Massachusetts, $597 \quad$ USA $<$ http://www.umass.edu/landeco/research/fragstats/fragstats.html $>$

598 Meyer CF, Struebig MJ, Willig MR (2015) Responses of tropical bats to habitat fragmentation, 599 logging, and deforestation. In Voight C, Kingston T (eds) Bats in the Anthropocene: 600 conservation of bats in a changing world. Springer, pp. 63-103

601 Meynard CN, Lavergne S, Boulangeat I, Garraud L, Van Es J, Mouquet N, Thuiller W (2013) 602 Disentangling the drivers of metacommunity structure across spatial scales. J Biogeogr 40: $603 \quad 1560-1571$

604 Mokany K, Ash J, Roxburgh S (2008) Functional identity is more important than diversity in 605 influencing ecosystem processes in a temperate native grassland. J Ecol 96: 884-893

606 Morrison DW (1978) Lunar phobia in a Neotropical fruit bat, Artibeus jamaicensis (Chiroptera: 607 Phyllostomidae). Anim Behav 26: 852-855

608 Oksanen J, Kindt R, Legendre P, O’Hara B, Simpson GL, Solymos P, Henry M, Stevens H, 609 Wagner H (2009) Vegan: community ecology package. R package version 1.15-4 
610 Organization for Tropical Studies (2012) La Selva daily rainfall, 1963-2010 (May11 update).

611 Organization for Tropical Studies, Meteorlogical Data, GPS Data and Hydrological Data.

$612<\mathrm{http}: / /$ www.ots.ac.cr/meteoro/default.php?pestacion=2>

613 Paradis E, Claude J, Strimmer K (2004) APE: analyses of phylogenetics and evolution in R 614 language. Bioinformatics 20: 289-290

615 Patterson BD, Willig MR, Stevens RD (2003) Trophic strategies, niche partitioning, and patterns 616 of ecological organization. In Kunz TH, Fenton MB (eds) Bat ecology. University of

617 Chicago Press, Chicago, Illinois, USA, pp. 536-579

618 Peres-Neto PR, Legendre P (2010) Estimating and controlling for spatial structure in the study of 619 ecological communities. Glob Ecol Biogeogr 19: 174-184

620 Peres-Neto PR, Legendre P, Dray S, Borcard D (2006) Variation partitioning of species data 621 matrices: estimation and comparison of fractions. Ecology 87: 2614-2625

622 Peres-Neto PR, Leibold MA, Dray S (2012) Assessing the effects of spatial contingency and 623 environmental filtering on metacommunity phylogenetics. Ecology 93: 14-30

624 Revell LJ, Harmon LJ, Collar DC (2008) Phylogenetic signal, evolutionary process, and rate. 625 Syst Biol 57: 591-601

626 Sih A (2011) Foraging theory. In Scheiner SM, Willig MR (eds) The theory of ecology.

627 University of Chicago Press, Chicago, Illinois, USA, pp. 65-90

628 Spasojevic MJ, Suding KN (2012) Inferring community assembly mechanisms from functional 629 diversity patterns: the importance of multiple assembly processes. J Ecol 100: 652-661

630 Stevens RD, López-González C, Presley SJ (2007) Geographical ecology of Paraguayan bats: 631 spatial integration and metacommunity structure of interacting assemblages. J Anim Ecol $632 \quad 76: 1086-1093$ 
633 Thies W, Kalko EKV (2004) Phenology of neotropical pepper plants (Piperaceae) and their 634 association with their main dispersers, two short-tailed fruit bats, Carollia perspicillata and 635 C. castanea (Phyllostomidae). Oikos 104: 362-376

636 Tschapka M (2004) Energy density patterns of nectar resources permit coexistence within a guild 637 of Neotropical flower-visiting bats. J Zool (London) 263: 7-21

638 Tscharntke T, Tylianakis JM, Rand TA, Didham RK, Fahrig L, Batáry P, Bengtsson J, Clough 639 Y, Crist TO, Dormann CF, Ewers RM, Fründ J, Holt RD, Holzschuh A, Klein AM, Kleijn 640 D, Kremen C, Landis DA, Laurance W, Lindenmayer D, Scherber C, Sodhi N, Steffan641 Dewenter I, Thies C, van der Putten WH, Westphal C (2012) Landscape moderation of 642 biodiversity patterns and processes - eight hypotheses. Biol Rev 87: 661-685

643 Vandewalle M, Bello F, Berg MP, Bolger T, Dolédec S, Dubs F, Feld CK, Harrington R, 644 Harrison PA, Lavorel S, Silva PM, Moretti M, Niemelä J, Santos P, Sattler T, Sousa JP, 645 646 647 biodiversity response to land use changes across ecosystems and organisms. Biodivers Conserv 19: 2921-2947

Weiher E, Keddy PA (1995) Assembly rules, null models, and trait dispersion: new questions from old patterns. Oikos 74: 159-164

Wilkinson GS (1985) The social organization of the common vampire bat. Behav Ecol Sociobiol 17: $111-121$

652 Willig MR, Presley SJ, Bloch CP, Hice CL, Yanoviak SP, Díaz MM, Chauca LA, Pacheco V, 653 Weaver SC (2007) Phyllostomid bats of lowland Amazonia: effects of habitat alteration on 654 abundance. Biotropica 39: 737-746 


\section{Figure legends}

657 Figure 1. Graphic illustrating variation partitioning of a response matrix or vector (Y) with 658 respect to two predictor matrices related to environment $(\mathrm{E})$ and space $(\mathrm{S})$. Total variation $(\mathrm{Y})$ is 659 partitioned into unique variation explained by $\mathrm{E}([\mathrm{a}]=[\mathrm{abc}]-[\mathrm{bc}])$, the fraction of variation 660 explained jointly by $\mathrm{E}$ and $\mathrm{S}([\mathrm{b}]=[\mathrm{abc}]-[\mathrm{a}]-[\mathrm{c}])$, unique variation explained by $\mathrm{S}([\mathrm{c}]=[\mathrm{abc}]$

$661-[a b])$, and variation not explained by either E or S ([d] = 1 - [abc]). Total variation (Y)

662 explained by different fractions is expressed in the following notation (after Legendre 1993):

663 [abc], environmental and spatial variation together; [ab], environmental variation; [bc], spatial

664 variation; [a], unique environmental variation after accounting for space; [b], spatially-structured 665 environmental variation; [c], unique spatial variation after accounting for environment; and [d], 666 residual variation.

667 Figure 2. Illustrations of (A) the mean location (composition) component and (B) the dispersion 668 component of functional or phylogenetic structure of a community that comprises species a, c, e, 669 and h. Species are mapped onto functional or phylogenetic space, and distances between pairs of 670 species quantify differences in species characteristics. (A) The composition component can be 671 represented by the centriod (blue dot) of the distribution of species. (B) The dispersion 672 component can be represented by the volume of space occupied by the community (blue shaded 673 region). Illustrations demonstrating that variation in functional or phylogenetic structure of three 674 communities (community 1, blue; community 2, green; community 3 , turquoise) can arise from 675 (C) differences in composition or (D) differences in dispersion.

676 Figure 3. Location of the 15 sampling sites (black dots) within the study landscape, as

677 represented by a 2011 land cover map. Location of the study landscape (black rectangle) in Costa 678 Rica is displayed in the upper-left corner of the land cover map. Alphabetical site codes 679 correspond with those in Fig. 5. 
680 Figure 4. Bar graphs represent the results of variation partitioning of (A) taxonomic structure

681 based on species composition, (B) functional dispersion based on all functional attributes, and

682 (C) phylogenetic dispersion for each combination of season (wet and dry) and scale (1, 3, and 5

$683 \mathrm{~km})$. The adjusted percentages of unique environmental effects [a], spatially-structured

684 environmental effects [b], unique spatial effects [c], and residual variation [d] are reported next

685 to each bar. Adjusted $R^{2}$ can be negative for any fraction and these are interpreted as zeros

686 (Legrendre 2008). Negative [b] fractions can occur when explanatory variables are correlated but

687 have strong and opposite effects on the response variable, or when explanatory variables have a

688 weak correlation with the response variable but strong correlation with other explanatory

689 variables that are correlated with the response variable (Peres-Neto et al. 2006). Significant

690 testable model fractions (i.e. unique effects) are indicated by superscript symbols (@, $0.10 \geq P>$

$691 \quad 0.05 ; *, 0.05 \geq P>0.01 ; * *, P \leq 0.01)$.

692 Figure 5. Dispersion of species abundances (represented by the intensity of gray) on the

693 supertree for bats at 15 sites within a human-modified landscape during the dry season and the

694 wet season, separately. Each column (positioned to the right of the supertree) represents a site.

695 Sites are organized from left to right based on decreasing degree of dispersion. Alphabetical site

696 codes correspond with those in Fig. 3. Clades representing five bat subfamilies are indicated by

697 numbered black dots (Stenodermatinae, 1; Carolliinae, 2; Glossophaginae, 3; Phyllostominae, 4;

698 Desmodontinae, 5). Dashed lines separate the five subfamilies to illustrate differences in the

699 representation of subfamilies along the gradient. 
$700 \quad$ Figure 1

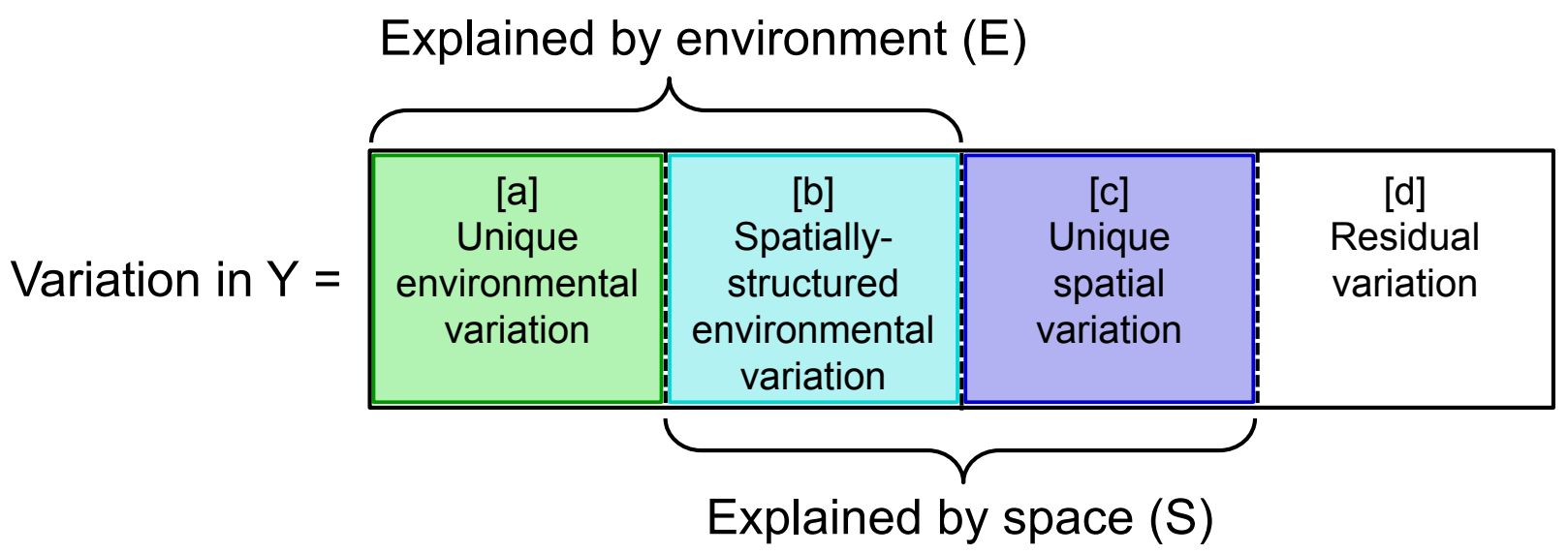

701 
702 Figure 2
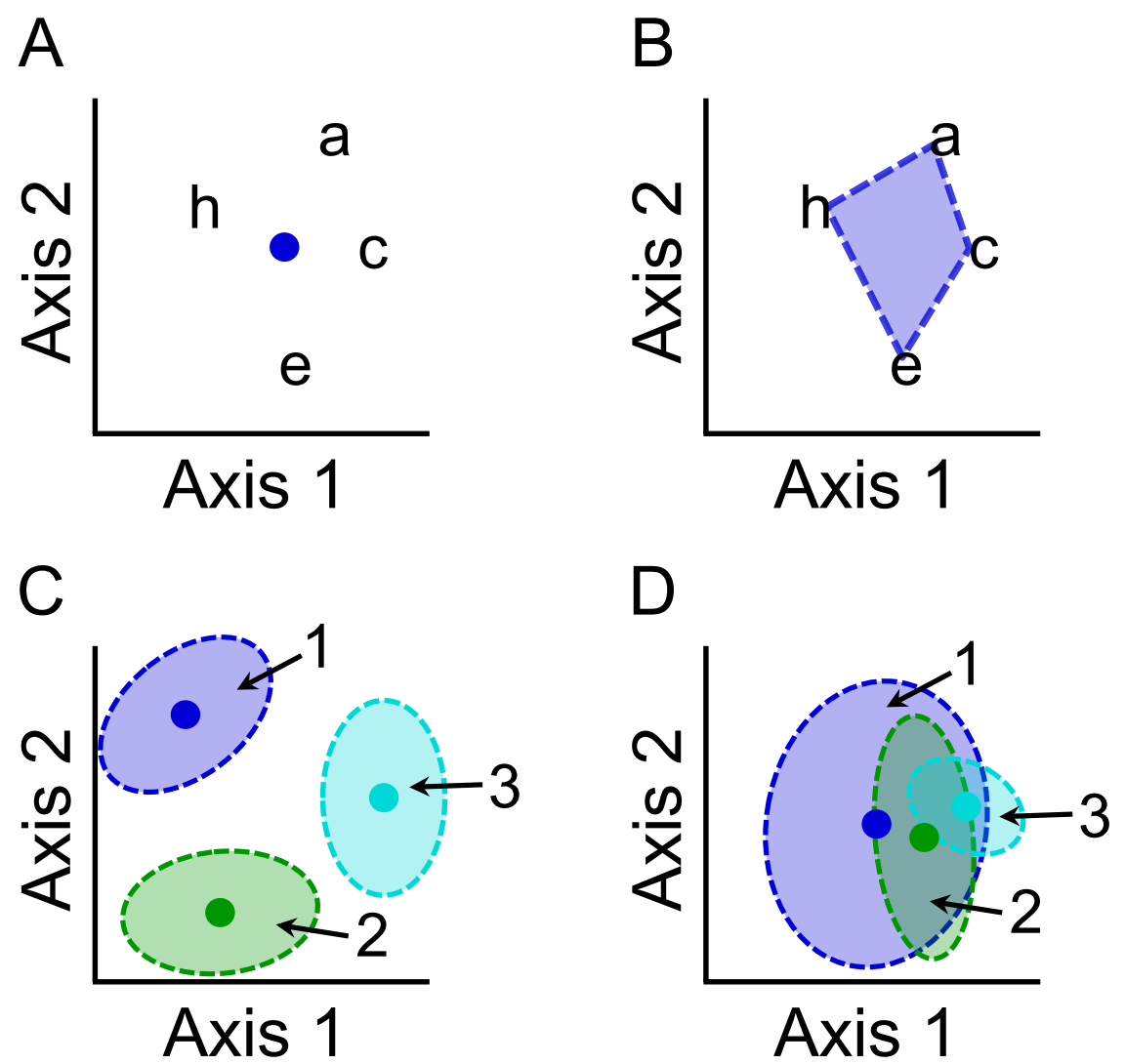
704 Figure 3

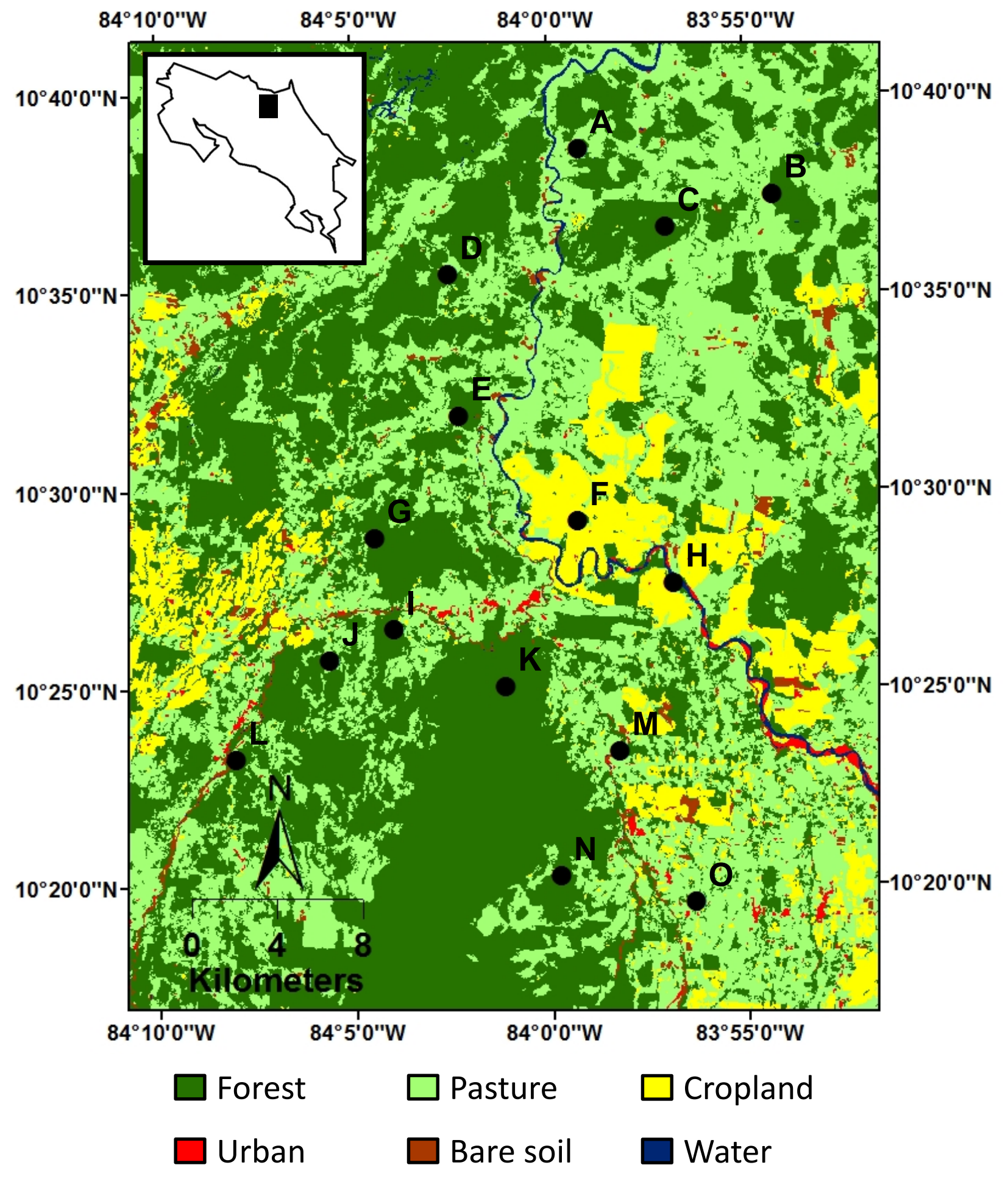


706 Figure 4

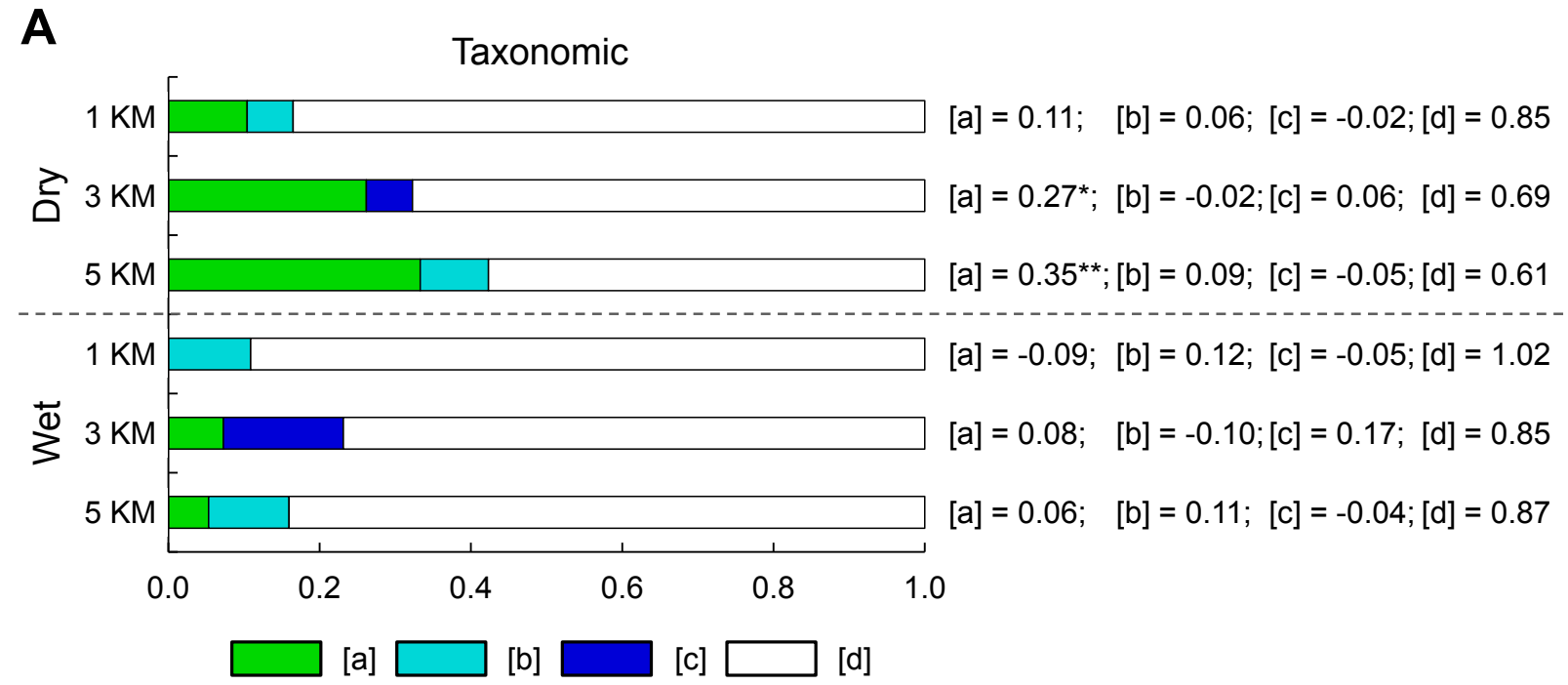

B

Functional
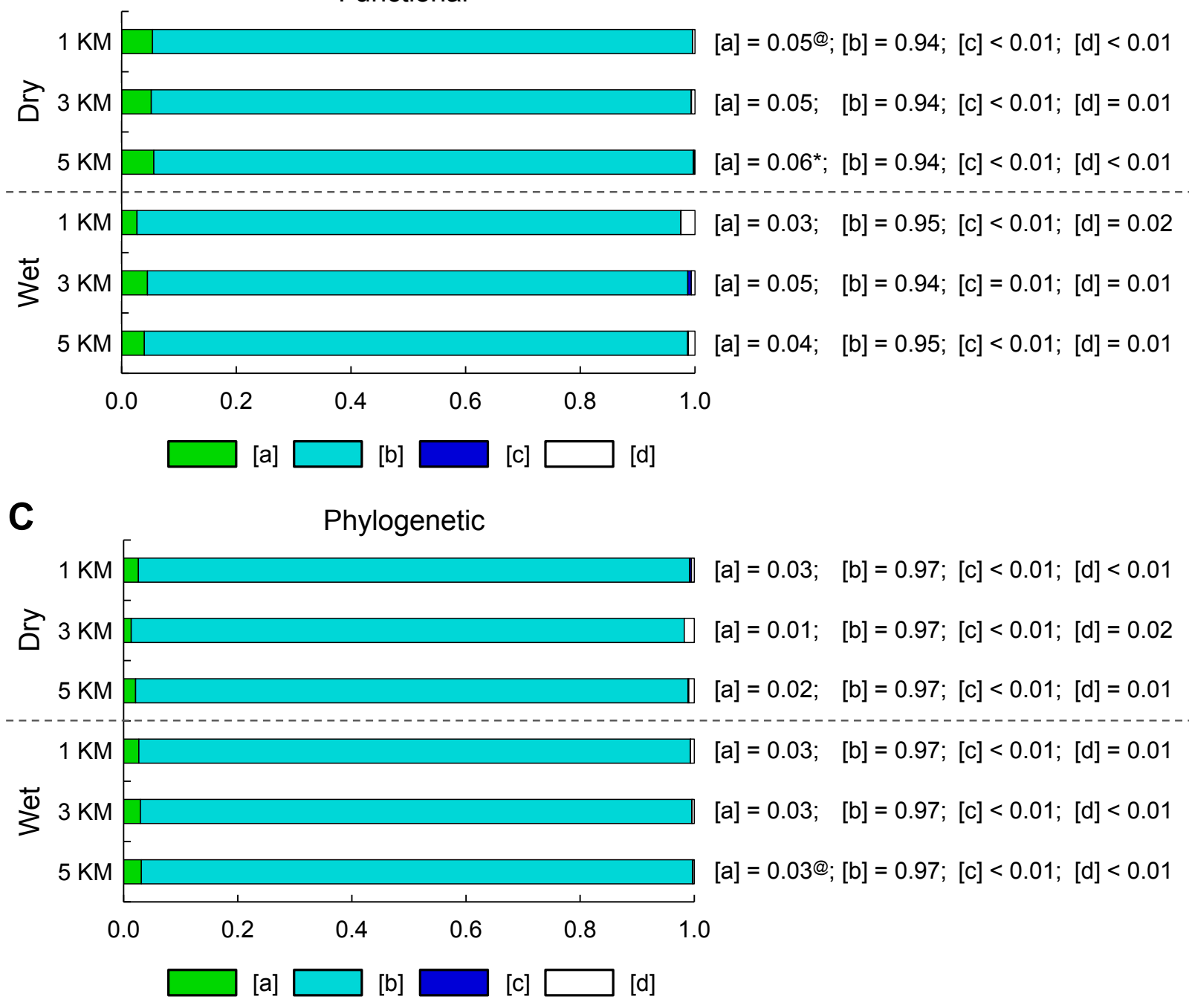
708 Figure 5
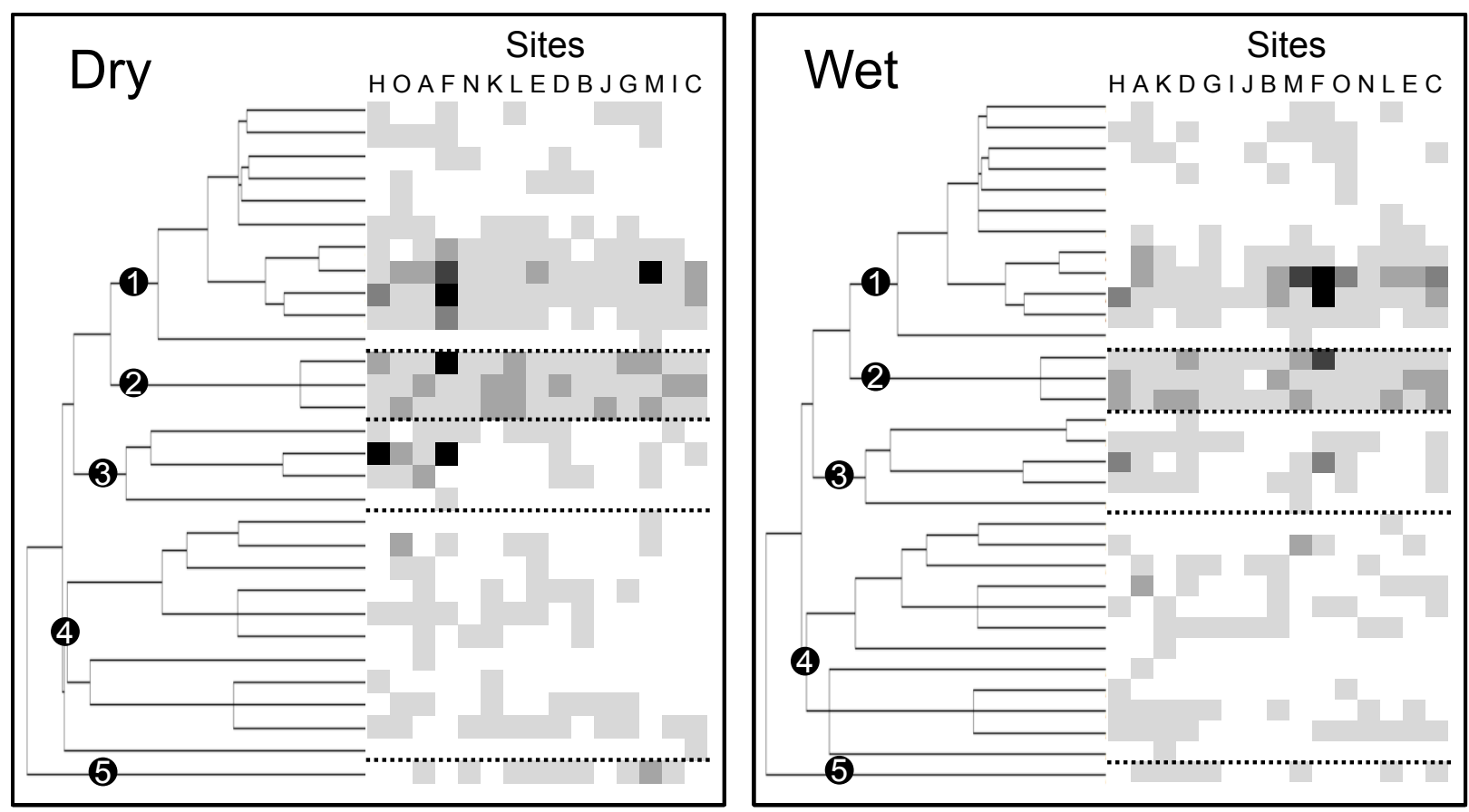

$\begin{array}{ccrc}1-10 \quad 11-20 \quad 21-30 & 31-40 & 41-50 \\ \text { Abundance } & \end{array}$

